ISSN $1014-4874$

DOI : http://dx.doi.org/10.4314/rj.v25i1.2

\title{
Potentiometric determination of Tantalum content in ores using an ion selective membrane electrode.
}

\author{
Kalisa Nyirimbibi*, Usanzineza Denise**, Uwamariya Valentine*, Sekomo Christian*a \\ * Faculty of Science, Department of Chemistry, National University of Rwanda \\ P.O. Box 117, Huye \\ ** Alex Stewart International Rwanda \\ a : corresponding author : csekomo@nur.ac.rw
}

\begin{abstract}
In this paper, a method for determination of tantalum in ores by direct potentiometry using an ion selective membrane electrode sensitive to the ion $\mathrm{TaF}_{6}$ has been proposed. After checking the Nernstian behavior of the electrode in the presence of $\mathrm{TaF}_{6}^{-}$, the influence of $\mathrm{NbF}_{6}^{-}$concentration on the determination of tantalum was also investigated. Potentiometric measurements on synthetic solutions of $\mathrm{TaF}_{6}^{-}$in the concentration range from $10^{-3}$ to $10^{-5} \mathrm{~mol}^{-1}$ were performed in the presence of $10^{-3} \mathrm{~mol}^{-1} \mathrm{l}^{-1}$ of $\mathrm{NbF}_{6}^{-}$as interferering ions. From the results recorded, it appeared that the response of the electrode deviate to the Nernstian behavior when $\mathrm{TaF}_{6}^{-}$concentration is less or equal to $5 \times 10^{-5} \mathrm{~mol}^{-1} \mathrm{I}^{-1}$ corresponding to a concentration of $\mathrm{NbF}_{6}{ }^{-}$at least twenty times greater than that of $\mathrm{TaF}_{6}^{-}$. Using the standard addition method, it was observed that the ion $\mathrm{NbF}_{6}^{-}$is no longer interferering with $\mathrm{TaF}_{6}^{-}$on the entire range of concentration of $\mathrm{TaF}_{6}^{-}$ investigated. The accuracy of the method conducted on a series of potentiometric measurements was about 1\%. The technique developed has then been applied to the determination of tantalum in samples of Colombo-tantalite from various region of Rwanda.
\end{abstract}

Key words: Potentiometry, Nernstian slope, tantalum, niobium, Colombo-tantalite.

\section{Introduction}

Tantalum is an element found in nature always associated with niobium (Aubouin et al., 1968). They are widely known to have similar chemical properties, thus for the determination of tantalum in a mixture of tantalum and niobium, it is most often offered to perform a preliminary separation (Cotton et al., 1988). Indeed, these two elements react very similarly with most common titrant reagents and selective masking of niobium is difficult to achieve.

A number of methods has been proposed to separate Tantalum from Niobium such as reversed phase high performance liquid chromatography 
(Vachirapatama et al., 2000, Narumol et al., 1999), extraction chromatography and paper chromatogram separation (Yang et al., 2002). Although these techniques are very selective, they suffer from heavy and complicated separation process and need a special instrument. Wang et al (2005) proposed a fast determination of of $\mathrm{Nb}$ and $\mathrm{Ta}$ with flow injection chemiluminescence method. In this method they could determine trace amounts of $\mathrm{Nb}$ and $\mathrm{Ta}$ in geological samples with satisfactory results.

Ion-selective electrode for the determination of tantalum have been developed. The response behavior of ions selective electrodes in terms of selectivity, precision, reliability, response time and life time are not well known, hence their applications are limited. Extraction-Spectrophotometric determination of tantalum using Brilliant Green-hexafluorotantalate(V) ion has been tested (Agrawal and John, 1985) but its application is not reported. In 1997, Amare et al., designed a new hexafluorotantalate (V) ion-selective liquid membrane electrode using brilliant greenhexafluorotantalate(V) ion-association complex in nitrobenzene with $\mathrm{PVC}$ support. The results showed that the electrode was highly selective and was responding to hexafluorotantalate $(\mathrm{V})$ ion over a wide linear range with Nernstian slope and short response time. However, the same results showed that this electrode had the traditional barrel-type configuration and requires an internal reference electrode system. To overcome this problem, Tewolde et al., (1997) conducted a study on the determination of Tantalum with hexafluorotantalate(V)-selective Coated Graphite Electrode. In fact, it has been found that some of the inherent problems associated with liquid membrane electrodes could be overcome by coating the sensing element on solid conductors such as silver, platinum, and graphite (Du et al., 2002).

Amare et al., (1997) also tried to develop an hexafluorotantalate(V)selective coated graphite electrode. This electrode was prepared by coating Malachite Green-hexafluorotantalate $(\mathrm{V})$ extract in 1-chloronaphthalene with a PVC matrix on a graphite rod. This electrode was found to be highly selective to hexafluorotantalate $(\mathrm{V})$ and free from interference of niobium which commonly occurs with tantalum. The analytical application of the electrode was extended to the determination of tantalum in tantalitecolumbite ores and several synthetic matrices using four potentiometric techniques and the results were in good agreement with the actual or certified values.

In this study Tantalum was determined by potentiometry using an indicator electrode in the ion-sensitive membrane $\mathrm{TAF}_{6}^{-}$. Since Niobium also forms a complex with fluoride ions $\left(\mathrm{NbF}_{6}{ }^{-}\right)$, it was proposed to study the influence of the concentration of this element on the determination of tantalum in 
mixture of tantalum and niobium first. Secondary the concentration of tantalum in the samples provided by Rwanda Metals was determined.

\section{Material and methods}

\subsection{Material}

\section{A) Sample preparation}

In order to determine tantalum in ores, samples require to be solubilised. This is achieved by use of concentrated sulfuric acid in the presence of $\mathrm{K}_{2} \mathrm{~S}_{2} \mathrm{O}_{7}$ as melting agent at high temperature.

\section{B) Experimental setup}

During this research, a reference electrode $\mathrm{Ag}^{+} / \mathrm{AgCl}$ double junction filled with $\mathrm{KCl} 3 \mathrm{~mol}$. / L was used together with an Ion-selective electrode in tantalum as indicative membrane electrode sensitive to the ion $\mathrm{TaF}_{6}{ }^{-}$see figure 1.

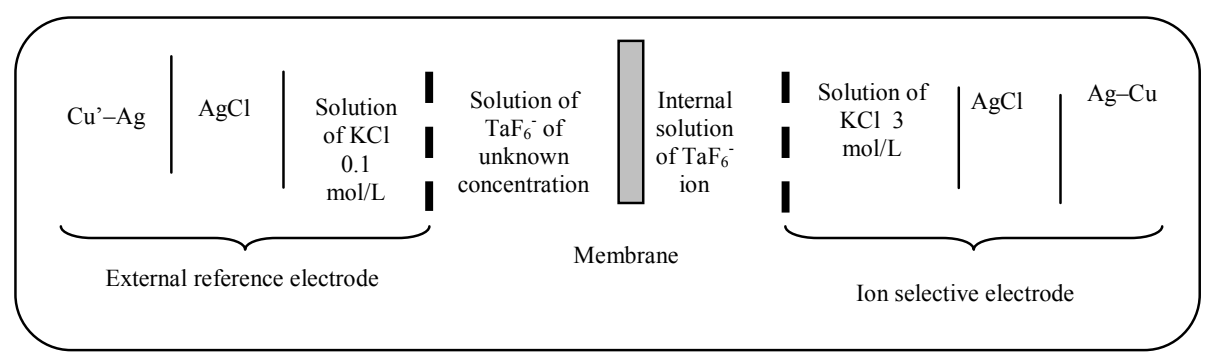

Figure 1: Potentiometric cell.

\subsection{Methods}

In order to detect a possible influence of niobium on tantalum determination, synthetic solutions of $\mathrm{TaF}_{6}^{-}$with concentrations of $10^{-5} \mathrm{~mol}$. / L, $2 \times 10^{-5}$ mol. / L, $5 \times 10^{-5} \mathrm{~mol}$. / L, $10^{-4} \mathrm{~mol}$. / L, $2 \times 10^{-4} \mathrm{~mol}$. / L, $5 \times 10^{-4}$ mol. / $\mathrm{L}$ and $10^{-3} \mathrm{~mol}$. / $\mathrm{L}$ each containing niobium at a concentration of $10^{-}$ ${ }^{3}$ mol. / L were used.

Two methods (direct potentiometry and standard addition methods) were used for $\mathrm{TaF}_{6}^{-}$determination. In the direct potentiometry method, the potential was directly read by putting the ion selective membrane device and the external reference electrode in the solution to be measured. In the standard addition method after thoroughly mixing of the sample solution, the potential $\mathrm{E}_{1}$ was measured. Then, after addition of $2 \mathrm{ml}$ of a $10^{-4} \mathrm{~mol}$. / $\mathrm{L}$ of the standard solution of $\mathrm{TaF}_{6}^{-}$the potential $\mathrm{E}_{2}$ of the ion selective electrode was again measured. 


\section{Results}

\subsection{Nernstian slope behavior}

To check the Nernstian behavior of the ion selective electrode $\mathrm{TaF}_{6}^{-}$, synthetic solutions of respective concentrations of $10^{-5} \mathrm{~mol}$. / L, $10^{-4} \mathrm{~mol}$. / $\mathrm{L}$ and $10^{-3} \mathrm{~mol}$. / $\mathrm{L}$ of this species were prepared. The variation of potential $\mathrm{E}$ measured for standard solutions versus $\log C_{\mathrm{TaF}_{6}^{-}}$is shown in figure 2 . This figure shows a line whose equation determined by application of the law of least squares has the form: $E=-0,392-0,0589 \log C_{T_{a F_{6}^{-}}}$(1). As it can be seen from the equation, the slope determined from this study was $0.0589 \mathrm{~V}$.

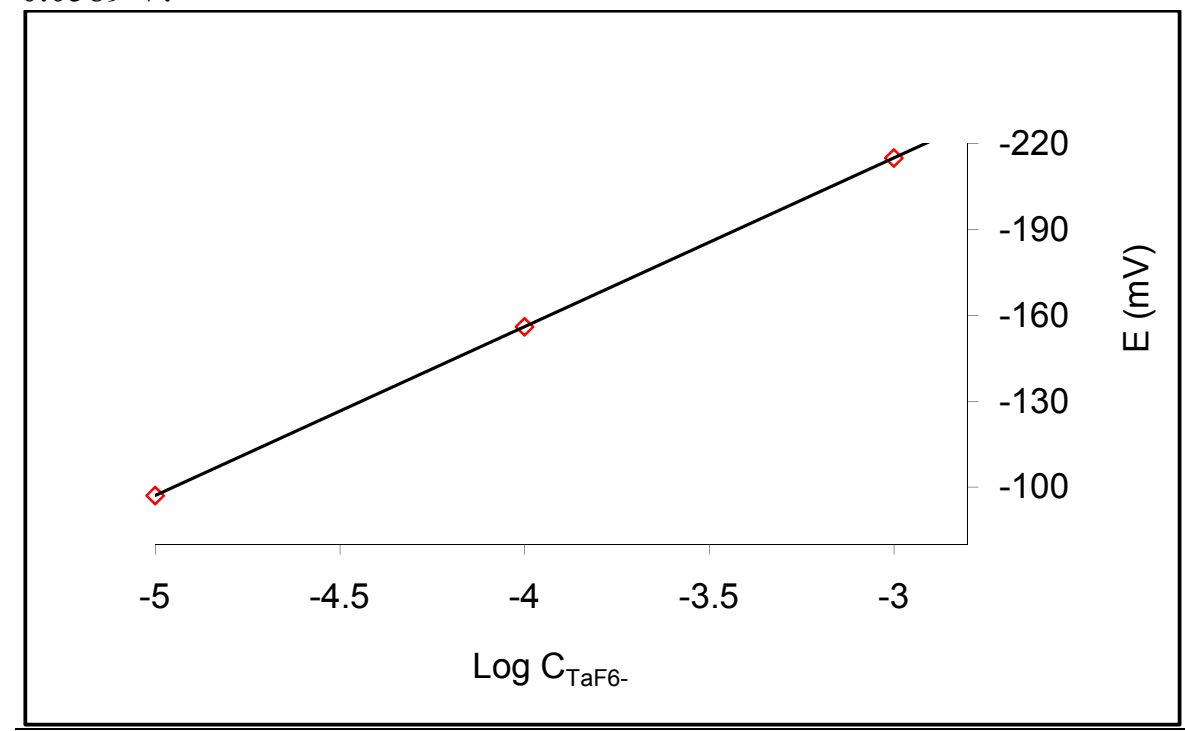

Figure 2: Variation of the electrode potential $\mathbf{E}$ versus $\log C_{\mathrm{TaF}_{6}^{-}}$

\subsection{Influence of $\mathrm{NbF}_{6}^{-}$concentration on $\mathrm{TaF}_{6}^{-}$determination.}

From this study, interference of Niobium onto Tantalum determination have been conducted on synthetic solutions of $\mathrm{TaF}_{6}^{-}$of concentrations ranging from $10^{-3} \mathrm{~mol} / \mathrm{L}$ to $10^{-5} \mathrm{~mol} / \mathrm{L}$ in the presence of $10^{-3} \mathrm{~mol} / \mathrm{L}$ of $\mathrm{NbF}_{6}^{-}$. Results from this study are shown in figure 3. From this figure, the deviation to the Nernstian slope of the ion selective electrode of the $\mathrm{TaF}_{6}^{-}$in the presence of the interfering ion $N b F_{6}^{-}$, occurs at a 
concentration lower to $5 \times 10^{-5} \mathrm{~mol} / \mathrm{L}$ of $\mathrm{TaF}_{6}^{-}$equivalent to twenty times less the concentration of $\mathrm{NbF}_{6}^{-}$.

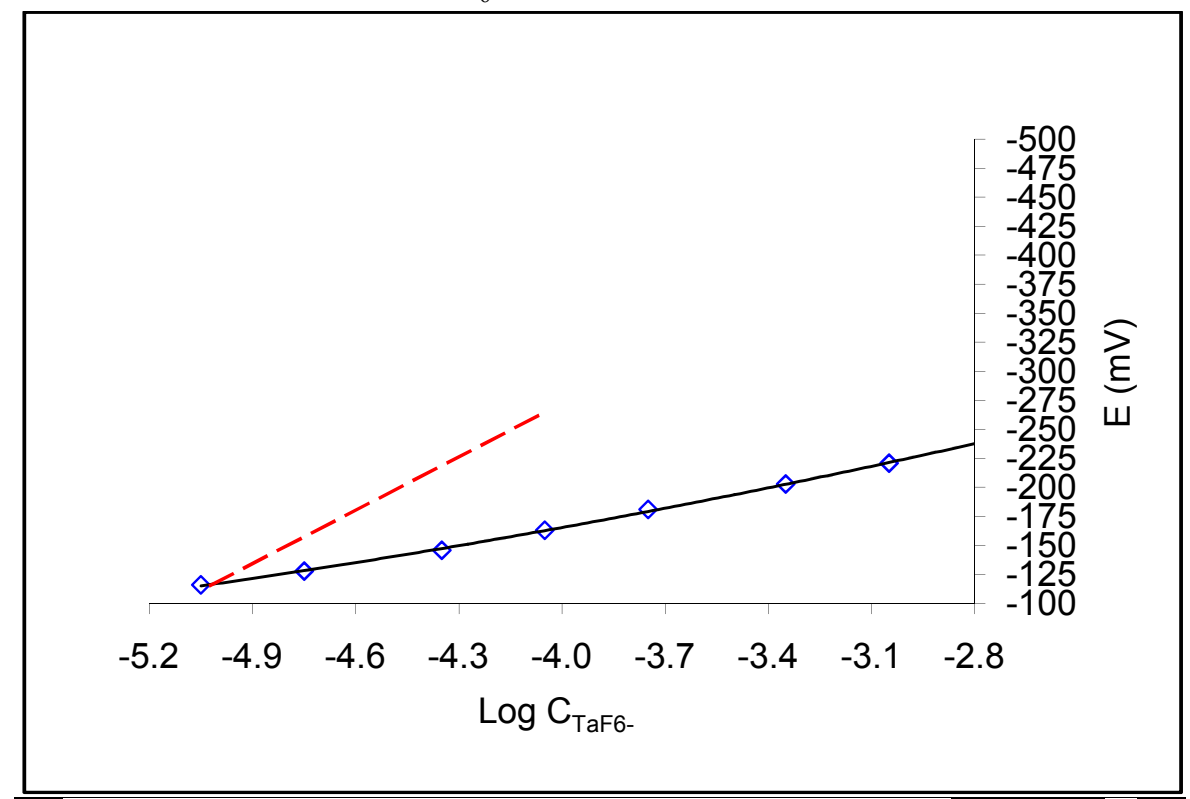

Figure 3: Variation of the electrode potential $\mathbf{E}$ versus $\log C_{T a F_{6}^{-}}$at constant $\mathrm{NbF}_{6}^{-}$.

\subsection{Influence of $\mathrm{NbF}_{6}^{-}$concentration by the standard addition method.}

To check the validity of this method, two successive standard additions have been conducted to a series of solutions of known concentrations of $\mathrm{TaF}_{6}^{-}$in the presence of $10^{-3} \mathrm{~mol} / \mathrm{L}$ of $\mathrm{NbF}_{6}^{-}$. Results from this study in figure 4 are showing a very good agreement between the values of the calculated concentration of $\mathrm{TaF}_{6}^{-}$and the series of prepared solutions. 


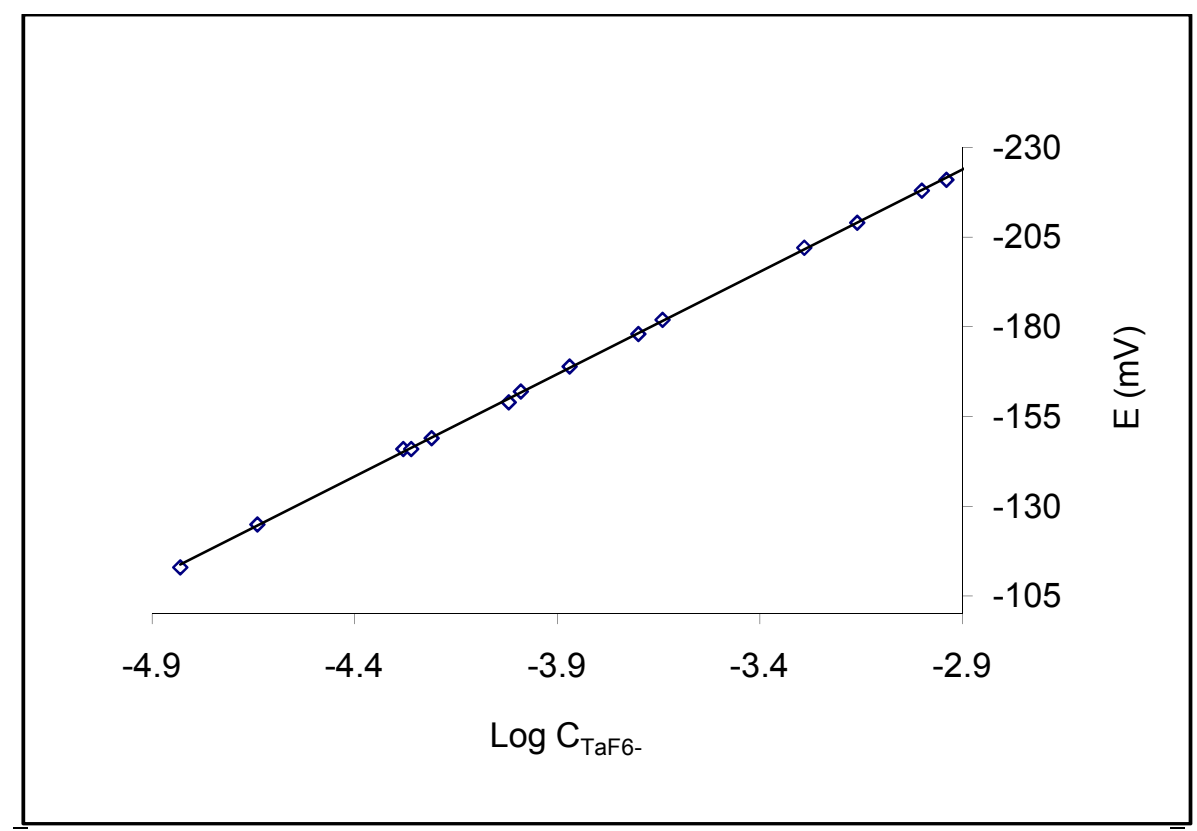

Figure 4: Variation of the electrode potential $E$ determined during the standard addition method versus $\log C_{T_{T a F_{6}^{-}}}$at constant $\mathrm{NbF}_{6}^{-}$.

\subsection{Tantalum determination in various ores from Rwanda}

The standard addition method was used for Tantalum determination for various ores from Rwanda. For each series of measurements were carried out not only to calibrate the experimental $\mathrm{TaF}_{6}^{-}$ion selective electrode to ensure proper operation but also to determine the tantalum content of a control sample whose content is $24.44 \%$ in $\mathrm{Ta}_{2} \mathrm{O}_{5}$. To improve the accuracy of the method a blank reading was performed. Tables 1, 2 and 3 are giving results from this study. 
Table 1: $\mathrm{Ta}_{2} \mathrm{O}_{5}$ content in samples from Mushubi, Rusoyo and Kirambo-Rugote

\begin{tabular}{|c|c|c|}
\hline & \multicolumn{2}{|l|}{$\% \mathrm{Ta}_{2} \mathrm{O}_{5}$} \\
\hline & sample 1 & sample 2 \\
\hline Blank sample & - & - \\
\hline Control sample & 24,47 & 24,47 \\
\hline Mushubi sample & 23,42 & 23.59 \\
\hline Rusoyo sample & 32,92 & 32,92 \\
\hline Kirambo - Rugote sample & 11,23 & 11,53 \\
\hline
\end{tabular}

Table 2: $\mathrm{Ta}_{2} \mathrm{O}_{5}$ content in samples from Ngara, Kirambo and Kabuye

\begin{tabular}{|c|c|c|}
\hline & \multicolumn{2}{|l|}{$\% \mathrm{Ta}_{2} \mathrm{O}_{5}$} \\
\hline & sample 1 & sample 2 \\
\hline Blank sample & - & - \\
\hline Control sample & 24,72 & 24,24 \\
\hline Ngara sample & 16,99 & 17,39 \\
\hline Kirambo sample & 27,23 & 27,63 \\
\hline Kabuye sample & 8,15 & 8,48 \\
\hline
\end{tabular}

Table 3: $\mathrm{Ta}_{2} \mathrm{O}_{5}$ content in samples from Kirambo - Wakiyumba, Kamabuye and Kabaya

\begin{tabular}{|c|c|c|}
\hline & \multicolumn{2}{|l|}{$\% \mathrm{Ta}_{2} \mathrm{O}_{5}$} \\
\hline & sample 1 & sample 2 \\
\hline Blank sample & - & - \\
\hline Control sample & 24,06 & 23,88 \\
\hline Kirambo - Wakiyumba sample & 22,16 & 22,57 \\
\hline Kamabuye sample & 26,66 & 26,01 \\
\hline Kabaya sample & 38,22 & 38,97 \\
\hline
\end{tabular}




\section{Discussion}

\subsection{Nernstian slope behavior}

The measured electrical potential difference $\mathrm{E}$ is connected to the activity of the species $\mathrm{TaF}_{6}^{-}$by the expression $E=E^{o}-2,3 \frac{R T}{F} \log a_{\mathrm{TaF}_{6}^{-}}$

with $\mathrm{E}^{\mathrm{o}}$ the standard potential corresponding to $a_{\mathrm{TaF}_{6}{ }^{-}}=1$. At a fixed ionic strength the expression becomes $E=E^{o}-2,3 \frac{R T}{F} \log C_{T a F_{6}^{-}}$(3). These expressions reflect the potential of a specific ion selective electrode $\mathrm{TaF}_{6}^{-}$ are identical to the Nernst equation. In fact, the graph representing the potential versus $\log C_{\mathrm{TaF}_{6}}$ is then a line with a slope equal to the Nernst coefficient $-2.3 \frac{R T}{F}(4)$ in the case of $T_{a F_{6}^{-}}$.

The Nernstian behavior of the ion selective electrode can easily be explained by interpretation of the plot given on figure 1 . In fact, the examination of this figure shows a line whose equation (1) was determined by the regression technique and the slope value thus determined was very close to the theoretical value of Nernst coefficient $-0.05915 \mathrm{~V}$ at $25{ }^{\circ} \mathrm{C}$. Therefore, the electrode used in this study showed a Nernstian behavior in the range of concentrations used for the calibration.

\subsection{Influence of $\mathrm{NbF}_{6}^{-}$concentration on $\mathrm{TaF}_{6}^{-}$determination.}

As defined by Barth \& Hedin, (1973) an ion selective electrode is a probe with a specific task of determining ion species, if possible independently of the presence of other ion species in the solution. In the case where the electrode is sensitive to other types of ions, it is an interference phenomenon. Under these conditions the response of the ion selective electrode $\mathrm{TaF}_{6}^{-}$in the presence of interfering ions $\mathrm{NbF}_{6}^{-}$is given by the expression:

$$
E=E o-2.3 \frac{R T}{F} \log C_{T a F_{6}^{-}}-2.3 \frac{R T}{F} \log \left(1+k_{T_{a F_{6}^{-}} / \mathrm{NbF}_{6}^{-}} \times \frac{C_{\mathrm{NbF}_{6}^{-}}}{C_{\mathrm{TaF}_{6}^{-}}}\right)(5)
$$

The gap between this ideal Nernstian slope to the ion $\mathrm{TaF}_{6}^{-}$, difference due to the non-specificity of the membrane is given by the expression: 
$-2.3 \frac{R T}{F} \log \left(1+k_{\text {TaF }_{6}^{-} / \mathrm{NbF}_{6}^{-}} \times \frac{C_{\mathrm{NbF}_{6}^{-}}}{C_{\mathrm{TaF}_{6}^{-}}}\right)(6)$

This difference depends on both the proportion of the ion $\mathrm{NbF}_{6}^{-}$compared to the ion- $\mathrm{TaF}_{6}^{-}$and the coefficient $k_{\mathrm{TaF}_{6}^{-}} \mathrm{NbF}_{6-}^{-}$(7), called potentiometric

selectivity coefficient of the membrane for the pair of ions $\mathrm{TaF}_{6}^{-} / \mathrm{NbF}_{6}^{-}$.

For this study, the limit of the Nernstian behavior for $\mathrm{TaF}_{6}^{-}$ions in the presence of the interferering ion $\mathrm{NbF}_{6}^{-}$appears at concentration below $5 \times 10^{-5} \mathrm{~mol} / \mathrm{L}$.

For concentrations higher than or equal to $5 \times 10^{-5} \mathrm{~mol} / \mathrm{L}$, the expression of he potential is:

$$
E=-0,394-0,0579 \log C_{T_{a F_{6}^{-}}}
$$

The slope is close to theoretical value of $-0.058 \mathrm{~V}$ at $20^{\circ} \mathrm{C}$. This was also the average value of temperature at which the study was realized.

\subsection{Influence of $\mathrm{NbF}_{6}^{-}$concentration by the standard addition method.}

The standard addition method involves measuring the potential of the ion selective electrode to determine the ion concentration before and after adding a volume of a standard solution to a given volume of the unknown solution. If $\mathrm{V}_{\mathrm{o}}$ and $\mathrm{v}$ are the respective volumes of the unknown and the standard solutions, Co and $\mathrm{C}$ their respective concentrations we may write the following expressions:

$$
\begin{aligned}
& E=E^{o}-2.3 \frac{R T}{F} \log C_{o}(9) \\
& E^{\prime}=E^{o}-2.3 \frac{R T}{F} \log \frac{V_{o} C_{o}+v C}{V_{o}+v}
\end{aligned}
$$

Where $\mathrm{E}$ and $\mathrm{E}$ are the potentials measured before and after addition of the volume of the standard to the volume $\mathrm{V}_{0}$ of the unknown solution. In solving the above system of equation we get the value of $\mathrm{C}_{0}$.

In figure 3 , shows the linearity recorded over the range of concentrations explored, hence it can be say that the ion selective electrode to the ion $\mathrm{TaF}_{6}{ }^{-}$ gave an ideal Nernstian response to the ion analyzed. The equation of the graph, calculated by the regression method was as followed: 
$E=-0,391-0,0575 \log C_{T_{a F_{6}^{-}}}$

It should be noted that the slope of this regression line was also close to the theoretical value of $-0.058 \mathrm{~V}$ at $20^{\circ} \mathrm{C}$.

To characterize the precision of the method, relative standard deviation has been calculated assuming that the sources of random error are the same for all measurements. This assumption is generally valid if samples have similar compositions and were analyzed in exactly the same way. For that matter, six determinations have been made from the control sample. The standard deviation of the sample was then calculated from this expression:

$S=\sqrt{\frac{\sum_{i=1}^{N}\left(X_{i}-\bar{X}\right)^{2}}{N-1}}$

The relative standard deviation was obtained by dividing the standard deviation by the average of the data series. When the relative standard deviation is multiplied by $100 \%$ is called variation coefficient VC.

$V C=\frac{S}{\bar{X}} \times 100 \%=\frac{0.31}{24.19} \times 100 \%=1.26 \%$

Therefore, it was clear the analysis method used has a good accuracy.

\section{Conclusion}

Potentiometric response of an ion selective electrode for a given ionic species implies the presence of that species within the membrane and its exchange between the membrane and the solution in contact. The ideal case is when the exchange between the electrode and the solution can only be happening for the ion for interest. Form this study the response of the ion selective electrode followed the Nernstian behavior between the concentration range from $10^{-3}$ to $10^{-5} \mathrm{~mol}$. / L. However, when $\mathrm{TaF}_{6}^{-}$ concentration was below $10^{-5} \mathrm{~mol} / \mathrm{L}$, interference from $\mathrm{NbF}_{6}^{-}$at $10^{-3} \mathrm{~mol}$. $/ \mathrm{L}$ was affecting the determination of Tantalum and the slope was deviating from the Nernstian behavior. In order to minimize the matrix effect on Tantalum determination, the standard addition method is recommended instead of the direct potentiometry method. The results obtained show that the electrode response was Nernstian in the range of concentrations from $10^{-3}$ to $10^{-5} \mathrm{~mol} / \mathrm{L}$ despite the presence of the interfering ion. The standard 
addition method was used for determination of Tantalum content in ores from various region of Rwanda. The accuracy of the method conducted on a series of potentiometric measurements was about $1 \%$.

\section{References}

1. Agrawal Y.K. and John S.T., (1985) Extraction-spectrophotometric determination of tantalum (V) with substituted N-arylhydroxamic acids, Analyst 110. pp. $1041-1042$.

2. Amare B., Chandravanshi B. S.; Moges G.; Megersa N. (1997), Hexafluorotantalate(V)-Selective Coated Graphite Electrode Based on Malachite Green. Analytical Letters, Volume 30 (3), pp. 457 - 474.

3. Aubouin J., Bousse R et Lehman J. (1968). Précis de géologie, tome 1 : Pétrologie. Paris, Dunod, pp. $44-61$.

4. Barthe M.L. et Hedin G. (1973). Chimie analytique I. Méthode électrochimiques, Paris, Armand colin, p. 174.

5. Cotton, F. A.; Wilkinson, G. (1988). Advanced Inorganic Chemistry $5^{\text {th }}$ ed. Wiley. p. 1385.

6. Du J.X., Li W.H., and Lu J.R., (2002), Flow injection chemiluminescence determination of thiamine based on its enhancing effect on the luminol-hydrogen peroxide system. Talanta 57, pp. $661-$ 665.

7. Narumol V., Miroslav M., Brett P., Carsten M., and Paul H., (1999), Determination of niobium $(\mathrm{V})$ and $\operatorname{tantalum}(\mathrm{V})$ as 4-(2pyridylazo)resorcinol-citrate ternary complexes in geological materials by ion-interaction reversed-phase high-performance liquid chromatography. Journal of Chromatography A, 850, p. 257.

8. Tewolde B., Chandravanshi B. S., and Moges G., (1997), Determination of Tantalum with Hexafluorotantalate(V)-selective Coated Graphite Electrode. Mikrochim. Acta 126, pp. 45 - 51.

9. Vachirapatama N., Dople P., and Haddad P.L., (2000), Separation and determination of niobium(V) and tantalum(V) as 2-(5-bromo-2pyridylazo)-5-[N-propyl-N-(3-sulfopropyl)amino]phenol citrate ternary complexes in geological samples using ion interaction highperformance liquid chromatography. Analytica Chimica Acta, 409, p. 35 . 
10. Wang H., Li J., Chen Z., Liu M., and Wang H., (2005), Fast simultaneous determination of Niobium and Tantalum by Kalman Filter Anlysis with Flow Injection Chemiluminescence Method, The Japan Society for Analytical Chemistry.

11. Yang J. X. and Pin C., (2002), Determination of niobium, tantalum, zirconium and hafnium in geological materials by extraction chromatography and inductively coupled plasma mass spectrometry, Analytica Chimica Acta 458, p. 375. 